\title{
REDUÇÃO DOS TEMPOS DE SET UP EM UMA LINHA DE PRODUTOS DE AÇO LAMINADOS À FRIO: UM ESTUDO DE CASO*
}

\author{
Ivan Rodrigues ${ }^{1}$ \\ Jose Luiz dos Santos ${ }^{1}$ \\ Renê de Oliveira França Filho ${ }^{1}$ \\ Rogério Fernandes da Costa ${ }^{1}$ \\ Karl Kristian Bagger ${ }^{2}$
}

\section{Resumo}

A eficiência operacional é um fator essencial para garantir a competitividade das empresas. O desafio é estudar os processos de forma a aumentar a sua produtividade sem necessidade de investimento, gerando valor as empresas. $O$ equipamento estudado, a Linha de Inspeção é o gargalo na produção limitando a geração de produtos em volume ou qualidade. As etapas eleitas para estudo foram os setup's das atividades de inicio (encaixe) e final (desencaixe) do processo, atividades não automatizadas, com maior intervenção humana que sofrem interferência direta dos tempos e métodos praticados pelos operadores. Utilizando o método dedutivo, tendo como ferramenta de apoio, a pesquisa bibliográfica para fundamentação teórica e realizadas observações de campo, determinou-se os melhores tempos para realização das atividades visando a sua otimização. $O$ presente trabalho tem como objetivo modificar o método operacional nesta Linha de Inspeção visando o aumento da eficiência produtiva, aumentando a geração dos laminados à frio. $O$ trabalho comprovou que a mudança do modo operacional proporciona um incremento de $8 \%$ na produção (1.800t/mes).

Palavras-chave: Tempos padrões; Redução dos tempos de Set up; Produtividade.

\section{SET UP TIME REDCUTION IN A COLD ROLLED STEEL PRODUCT LINE Abstract}

Operational efficiency is a key factor to ensure the competitiveness of enterprises. The challenge is to study the process in order to increase its productivity without investment value generating companies. The equipment studied, the inspection line is the production bottleneck limiting the generation of product by volume or quality. $\mathrm{s}$. The steps were elected to study the set-up's of start (threating) and final (realease) of the process, not automated activities, more human intervention that suffer direct interference of the times and methods practiced by operators. Using the deductive method, and as a support tool, the literature for theoretical foundation and conducted field observations, it was determined the best times for carrying out activities aimed at optimization. This work aims to modify the operating method in this inspection line in order to increase production efficiency, increasing the generation of the cold rolled. The work proved that the operating mode change provides an increase of $8 \%$ in production $(1,800 t /$ month $)$

Keywords: Times patterns; Set-up time reduction; Productivity.

1 Técnico Siderúrgico,USIMINAS Cubatão Formando em Engenharia de Produção UNIMONTE,Santos, SP Brasil

2 Engenheiro Metalurgista FEI, Especialista em Siderurgia POLI-USP, Professor Asssitente UNIMONTE Santos, SP Brasil. 


\section{INTRODUÇÃO}

Nos dias de hoje, para que as empresas possam ser competitivas num mercado globalizado torna-se fundamental que reduzam seus custos e consequentemente maximizem os lucros, torna-se necessário buscar dentro de seus processos o máximo de eficiência dos equipamentos. Em um fluxo continuo, as linhas subsequentes com menor capacidade produtiva represam a demanda, gerando os conhecidos gargalos, com isto provocando a diminuição da oferta ao mercado de produtos com valor, restringindo a margem de lucros da organização. Realizou-se este estudo de otimização do método operacional de uma linha de inspeção de uma indústria siderúrgica, atuando nos tempos de set up, com o foco no aumento da produtividade, visando, desta forma, proporcionar aumento da oferta ao mercado do volume de produtos laminados à frio, com garantia de acabamento e inspeção final.

\section{DESENVOLVIMENTO}

\subsection{Conceitos de tempos e métodos de padronização}

Segundo Campos (2009) uma das causas dasdificuldades de se obter bons resultados nos processos produtivos está arrolada com a gestão das atividades como, por exemplo, a inexistência de faixas de especificações para os indicadores operacionais, a ambiguidade na definição destas faixas ou a inexistência de padrões de qualidade e de treinamento para o cumprimento destes padrões. Outros problemas podem estar ligadosa causas rotativas ou especiais que afetam o funcionamento do processo e que, à medida que são eliminadas, tornam a produção cada vez mais confiável.

Neste trabalho, o foco da avaliação e da proposta a ser apresentada será no tempo de produção, o que impactará na capacidade produtiva do equipamento. A avaliação poderá indicar alterações em procedimentos respeitando a qualidade determinada pelo processo.

\subsection{Estudo de Tempo e métodos - Tempos Cronometrados}

A cronometragem é um dos métodos mais empregados na indústria para medir o trabalho. Em que pese o fato do mundo ter sofrido consideráveis modificações desde a época em que F. W. Taylor estruturou a Administração científica e o estudo de tempos cronometrados, objetivando medir a eficiência individual, essa metodologia continua sendo muito utilizada para que sejam estabelecidos padrões para a produção e para os custos industriais.

\section{METODOLOGIA}

\subsection{Procedimentos para o estudo de caso}

As ações para o levantamento dos dados analise e proposta de melhorias seguiram os seguintes passos:

\section{$\checkmark$ Definição dos tempos de set up}

Para a definição dos tempos de set up foi necessário o integral entendimento dos equipamentos que compõem a linha de inspeção, desde a sua 
importância dentro da linha de produção de aços laminados, até o seu pleno funcionamento.

$\checkmark$ Monitoramento dos tempos de Set Up

A obtenção de informações pode interferir diretamente nos resultados, por este motivo deverá ser avaliada a possibilidade de extrair informações de um sistema de monitoramento do próprio equipamento através de sistema supervisório. Os dados colhidos neste processo deverão manter sempre a sua integridade e relatar especificamente os fatos (tempos) ocorridos.

$\checkmark \quad$ Análise dos turnos e dos tempos de Set Up

Após o balizamento das informações, uma análise das melhores médias de tempos de cada turno devem ser identificadas, dentro dos tempos de set up em que haja interferência direta da ação do homem. Em seguida os turnos que tenham melhores resultados médios, ou seja, os menores tempospara a execução de suas atividades dentro de cada set up devem ser avaliados para a identificação dos procedimentos e sua utilização como benchmarking interno.

$\checkmark$ Identificação dos procedimentos com melhor desempenho

Os Set Up's com melhor desempenho em relação a tempo devem passar por uma análise detalhada das formas de execução dos procedimentos ou métodos de execução de cada Set Up. Em seguida deverão ser comparadas as principais diferenças entre os turnos de melhor desempenho em relação aos demais.

Devem ser observadas as diferenças procedimentais e estas devem ser corelacionadas com os desempenhos de tempo objetivando a identificação do melhor desempenho entre cada equipe

\section{$\checkmark$ Estimativas de ganhos}

Caso defina-se que existe a possibilidade de otimização do processo alterando-se apenas procedimentos ligados diretamente aos setup's e com base na diferença entre o tempo médio de execução, menos o tempo médio do procedimento mais veloz, será possível mensurar o potencial de material que poderá ser fabricado em virtude da padronização entre os turnos de trabalho.

\section{ESTUDO DE CASO: LINHA DE INSPEÇÃO 2 DA LAMINAÇÃO A FRIO}

No fluxo siderúrgico estudado, a Laminação a Frio tem como finalidade processar as bobinas de aço de diferentes espessuras oriundas da Laminação a Quente, ao final do fluxo de produção as bobinas, produtos acabados são direcionadas às Linhas de Inspeção, onde é realizada sua inspeção final, contemplando os aspectos superficiais, dimensionais e de forma da tira, garantindo assim especificações solicitadas pelos clientes.

\subsection{Capacidades Produtivas}

As capacidades produtivas na fabrica estudada estão descritos na tabela 1: 
Tabela 1- Capacidades Produtivas Fonte: Elaborado pelo autor, 2015

\begin{tabular}{l|c}
\multicolumn{1}{c|}{ Equipamento } & Capacidade Produtiva \\
\hline Decapagem & $140.000 \mathrm{t} / \mathrm{mês}$ \\
\hline Laminador de Tiras à Frio (LTF) & $110.000 \mathrm{t} / \mathrm{mês}$ \\
\hline Recozimento & $110.000 \mathrm{t} / \mathrm{mês}$ \\
\hline Laminador de Encruamento & $110.000 \mathrm{t} / \mathrm{mês}$ \\
\hline Linha de Inspeção I & $45.000 \mathrm{t} / \mathrm{mês}$ \\
\hline Linha de Inspeção II & 30.000 t/mês \\
\hline
\end{tabular}

Com isto, nota-se então, que as Linhas de Inspeção, com menor capacidade produtiva, em torno de $37,5 \%$ a menos que o equipamento anterior, o Laminador de Encruamento, é o maior fator limitante no fluxo de produção da Laminação a Frio. Quando a demanda assim o exige, ou seja quando o programa mensal de produção ultrapassa a capacidade máxima das Linhas de Inspeção, parte da geração de produtos é realizada no Laminador de Encruamento, restringindo a um mix de produto com menor valor agregado. Desta forma o aumento da eficiência desta linha reflete em aumento de produtividade sem aumentar os custos operacionais com instalação de novos equipamentos.

\subsection{Linha de Inspeção 2}

A Linha de Inspeção $n^{\circ} 2$, a qual é o tema deste estudo tem como principais equipamentos estão distribuídos na linha conforme lay out da Figura 1.

Figura 1- Lay Out da Linha de Inspeção 2

Fonte: Elaborado pelo autor, 2015

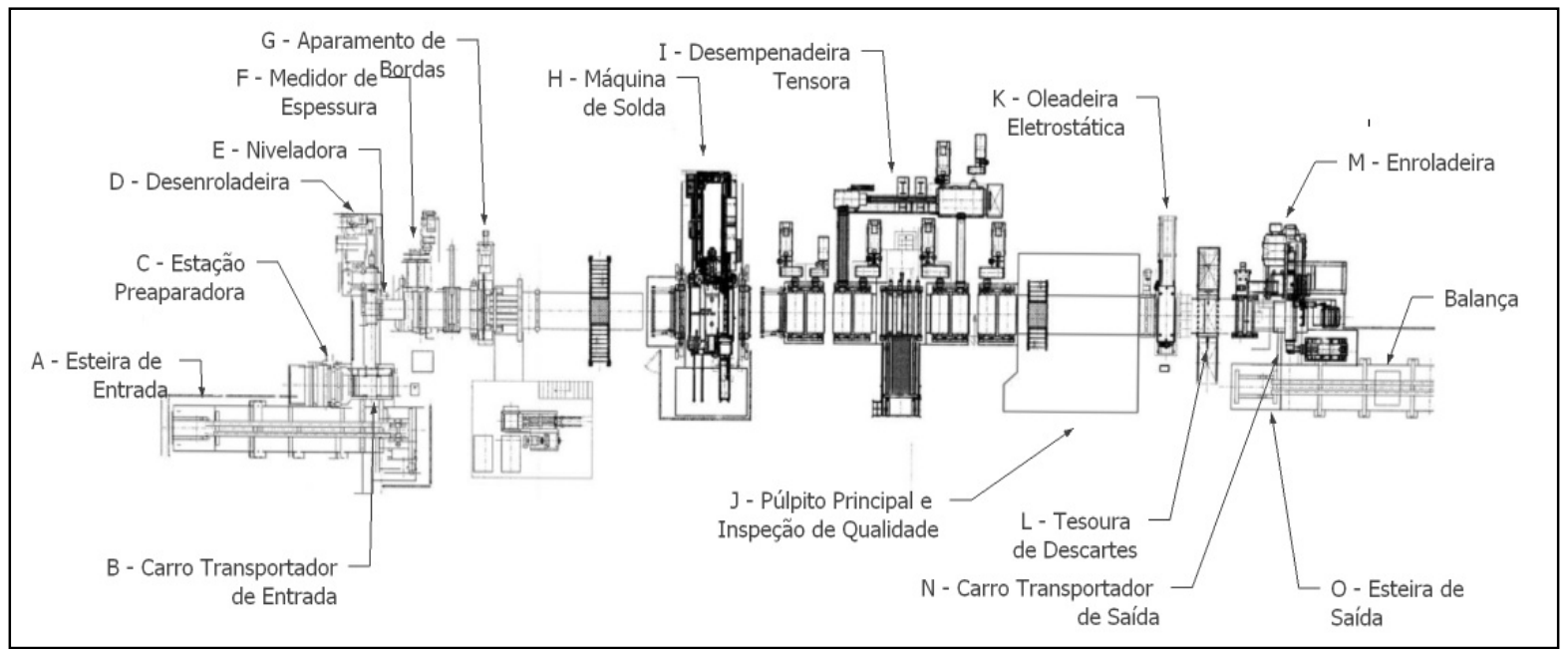

O processo da tem início com o recebimento do programa de produção, a localização dos rolos conforme o programa e abastecimento destes na esteira de entrada pela Ponte Rolante, após solicitação operacional.

A esteira de entrada é acionada e os rolos são deslocados até a posição de acesso do carro transportador de entrada. Os rolos são então transportados para a estação preparadora onde as pontas defeituosas são cortadas e a ponta da tira preparada para o encaixe na enroladeira. Após esta operação, o rolo é transportado para uma 
posição de espera previamente alinhado ao mandril, aguardando o final do rolo em processo para ser encaixado na enroladeira.

Ao final do rolo em processo, o mandril da enroladeira é contraído para receber o próximo rolo, movimentado pelo carro transportador. Em seguida o mandril é expandido e uma operação de aperto do miolo do rolo é realizada, para evitar o escorregamento das espiras durante o processo.

$\mathrm{Na}$ sequência, através da movimentação da Desenroladeira, a ponta da tira é desbobinada, passando pela niveladora onde será aplainada caso seja necessário. Seguindo o fluxo, o material passa pelo medidor de espessura online, que foi previamente programado com as características do material em processo.

Se o pedido do material assim o exigir, deverá ocorrer o ajuste de largura no sistema de aparamento de bordas.

Após esta etapa, a ponta da tira é deslocada até a máquina de solda para ser soldada com a ponta final da tira do rolo anterior que foi previamente preparada para esta operação. Após a soldagem das pontas, esta é inspecionada para verificação da sua qualidade e liberada, sendo então a tira deslocada para a saída em movimento de marcha. Caso a solda não seja liberada, será refeita.

No posto da inspeção de qualidade, o inspetor avalia a qualidade do final da tira e define o momento em que a linha deve parar e iniciar o processo de descarte das pontas que se encontram fora do padrão de aprovação, até a região da solda, estas pontas são direcionadas para uma caçamba apropriada.

Após o descarte da solda, através de instrumentos de medição manual, as dimensões do material são confirmadas pelo inspetor de qualidade e em seguida o encaixe da tira na enroladeira é liberado. Inicia-se então o processo em regime do rolo que foi encaixado na desenroladeira. Já no início deste processo, caso haja necessidade, a utilização da desempenadeira tensora é definida pelo inspetor de qualidade, com o objetivo de melhorar a forma do material.

A bobina formada pela metragem programada tem a tira seccionada na tesoura de descartes e é enrolada para posicionamento adequado da ponta. O mandril da enroladeira é contraído e a bobina é removida para a esteira de saída através do carro transportador.

Nas esteira de saída a bobina é deslocada até a posição correta para o cintamento e em seguida direcionada para a posição da balança, onde é pesada e recebe uma etiqueta com o número de identificação, o peso, as dimensões e o

\subsubsection{Definição dos tipos de set up da linha de inspeção 2}

Analisando as fases em que se divide o processo, em encaixe, processo e desencaixe, verificou-se que o tempo de setup da linha focalizam-se em duas fases e que ele pode ser dividido em 9 etapas que coincidem com as atividades realizadas pelo operador ao longo do processo como visualizado do diagrama da Figura 2.

Figura 2 - Set-up na Linha de Inspeção 2.

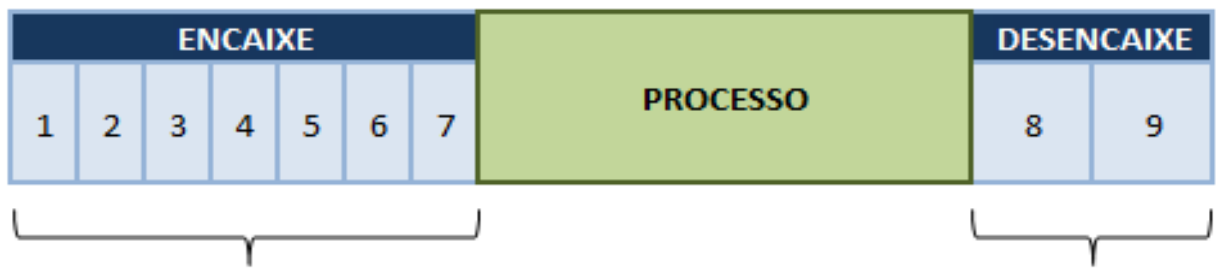

ETAPAS DE SET-UP

SET-UP

Fonte: Elaborado pelo autor, 2015 
A figura 3 mostra a estrutura da linha para identificação física das etapas:

Figura 3 - Estrutura da linha para identificação física das etapas

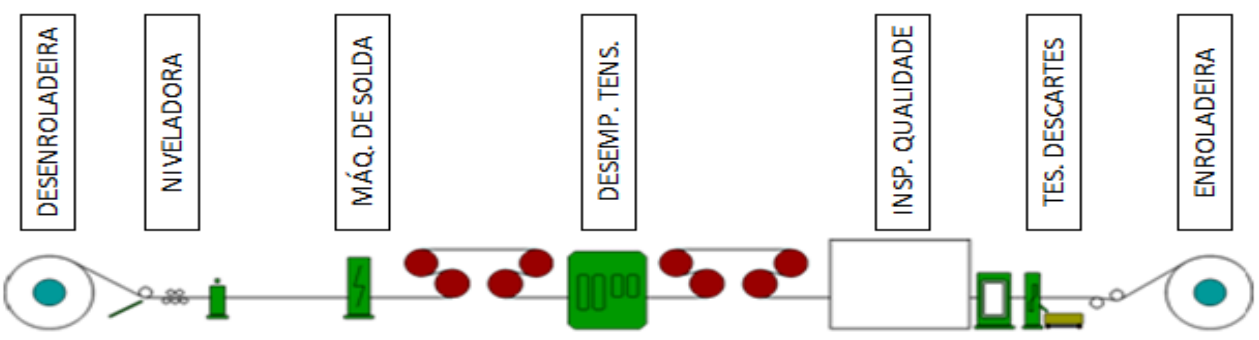

Fonte: Elaborado pelo autor, 2015

Etapa 1 - Encaixe do rolo na desenroladeira

Inicia no momento que a ponta final do material que está em processo na linha passa pela niveladora e termina quando a ponta inicial do novo rolo que está na desenroladeira passa pela niveladora.

Etapa 2 - Deslocamento da ponta da tira até a máquina de solda

Inicia no momento que a ponta inicial do novo rolo passa pela niveladora e termina quando a ponta chega à máquina de solda.

Etapa 3 - Solda das pontas

Inicia no momento que a ponta inicial passa pelo sensor de entrada da máquina de solda e termina quando a linha se movimenta para inspeção da solda.

Etapa 4 - Inspeção da solda

Inicia no momento que a solda estaciona na saída da máquina para inspeção do operador e termina quando o operador aciona a linha para posicionar a solda à mesa de inspeção.

Etapa 5 - Deslocamento da solda até a saída

Inicia no momento que o operador aciona a linha para posicionar a solda na mesa de inspeção e termina quando a solda chega à mesa.

Etapa 6 - Inspeção do final da tira

Inicia no momento que a solda sai da mesa de inspeção e termina após o corte da tesoura de saída e a ponta final da bobina passa pelo rolo defletor de saída.

Etapa 7 - Descarte do material

Inicia no momento que a ponta final da bobina passa pelo defletor de saída e termina após o descarte a ponta inicial e a nova bobina passa pelo defletor de saída.

Etapa 8 - Encaixe da ponta na enroladeira

Inicia no momento que a ponta inicial da nova bobina é encaixada no mandril e termina quando a linha entra em marcha (passa de $50 \mathrm{rpm}$ ).

Etapa 9 - Desaceleração final e ponta fora da desenroladeira

Iniciano momento que a linha desacelera até $50 \mathrm{mpm}$ (metros por minuto) e termina quando a ponta final do material que está em processo na linha sai do mandril da desenroladeira e passa pela niveladora.

\subsubsection{Definição dos parâmetros de coleta de dados}

A qualidade no processo de coleta de dados foi de extrema importância no desenvolvimento do projeto, para definir os tempos reais praticados em cada etapa, estratificando entre as equipes os melhores tempos já praticados. Para se obter um resultado mais confiável, foi necessário analisar não somente os tempos de set up das equipes, mas incorporar a análise os impactos do mix de produção, necessitando definir as variáveis dos produtos a serem estudados, os quais 
alinhados com as equipes de operação, chegou-se nas seguintes faixas de material, descritas na Tabela 2:

Tabela 2 - Faixas de espessura e largura

\begin{tabular}{c|c|c}
\hline Variáveis & Espessura & Largura \\
\hline \multirow{2}{*}{ Faixas } & $<0,60 \mathrm{~mm}$ & $<1000 \mathrm{~mm}$ \\
& $>=0,60 \mathrm{e}<1,90 \mathrm{~mm}$ & $>=1000 \mathrm{~mm}$ \\
& $>=1,90 \mathrm{~mm}$ & \\
\hline
\end{tabular}

Fonte: Elaborado pelo autor, 2015

\subsection{Coleta de Dados}

O sistema de supervisão e controle da linha foi utilizado para aquisição dos dados tratados neste trabalho, ele permitiu uma homogeneidade e precisão nos valores adquiridos. Desta forma foram coletados dados de aproximadamente 9.910 bobinas processadas. Os dados analisados fazem parte de uma gama de material de borda natural (sem o aparamento de bordas), pois estes foram $89 \%$ de todo material processado no período aquisitivo, para garantir a consistência do estudo. A partir disto, utilizou-se ferramentas estatísticas para validação e análise dos dados.

Com base nos valores obtidos, foi verificada a média do set up da somatória de todas as etapas para as três faixas de espessura nas duas faixas de largura. Os resultados apresentados na figura 5 estão separados por espessura sendo obtidos a partir da média de 1.397 amostras (largura >= 1000mm) e 8.067 amostras (largura < $1000 \mathrm{~mm})$.

Figura 5 - Tempo médio de set up

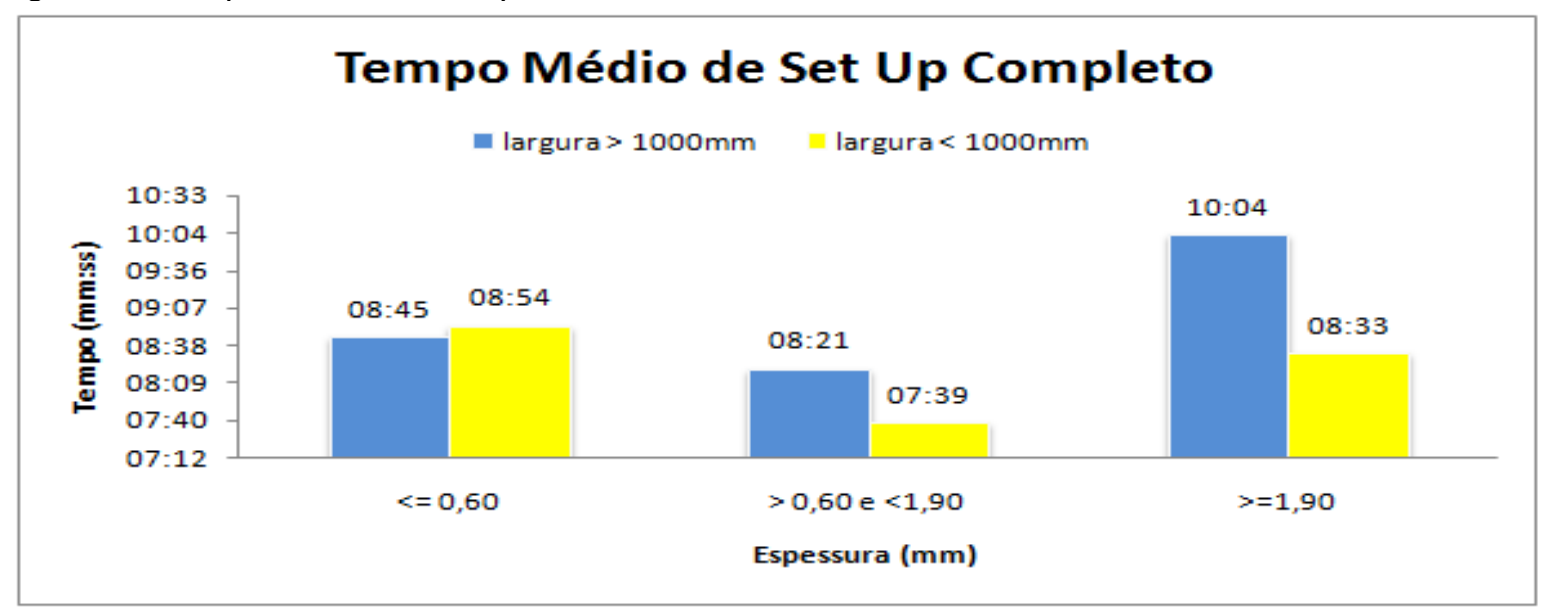

Fonte: Elaborado pelo autor, 2015

Analisando os dois gráficos, percebe-se que até a espessura de 1,90 $\mathrm{mm}$ há um equilíbrio em ambas as faixas de largura, ocorrendo uma elevação nos materiais de largura maior e igual que $1000 \mathrm{~mm}$ na faixa de espessura $\geq 1,90 \mathrm{~mm}$. Este item será mais abordado no momento das estratificações detalhas de cada etapa

Baseados nesta linha de estudo, foram agrupados os dados dos tempos de set up de todas as etapas considerando a divisão por turmas de trabalho, por faixas de espessura e de largura, sendo possível identificar qual o desempenho das equipes na tomada de tempo total de preparação. 


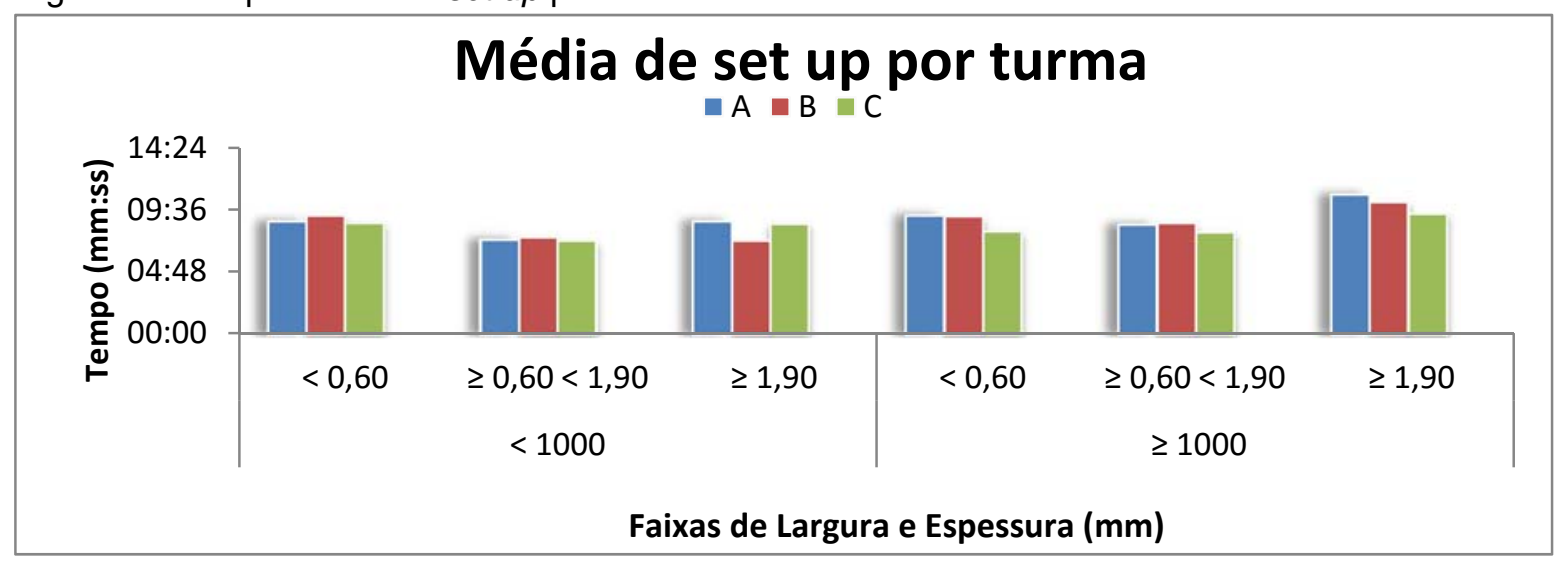

Fonte: Elaborado pelo autor, 2015

Estes resultados mostram que apesar dos turnos trabalharem dentro dos padrões operacionais, algumas equipes desenvolvem métodos distintos de trabalho mostrando eficiência e otimização dos tempos de set up quando analisados em conjunto.

\subsection{Definição das atividades críticas}

Partindo do princípio que os pontos críticos no tempo de set-up da Linha são aqueles de maior dependência da ação do operador, necessitou-se realizar um filtro dentro de todas estas etapas para definir as atividades mais criticas e concentrar o estudo na observação nas interferências causadas pelas demoras operacionais. Como forma de estudo, ficou definido que a média realizada pelo turno mais eficiente deve ser considerada como tempo padrão para o benchmarking interno na busca de aumento da eficiência da linha, assim sendo, identificamos particularidades em cada etapa, das quais definem também a sua importância e foco dos estudos.

A etapa 1, bastante dependente da atuação do operador de entrada, necessita de uma preparação prévia do rolo, atenção ao final do processo e habilidade para encaixe da ponta inicial do novo material a ser processado, considerada relevante para os estudos.

A distribuição dos dados pesquisados, mostra que aproximadamente $24 \%$ ficaram acima de 90 segundos, de forma que, atuando na padronização e treinamento dos operadores para que estes 2.353 rolos atinjam o tempo padrão para cada especificidade de material, a redução estimada no tempo da etapa 1 é de aproximadamente 1 hora e 44 minutos em um mês. A Tabela 3 - Tempo padrão da etapa 1 contém o tempo médio realizado pela equipe da turma $\mathrm{C}$ que apresentou $\mathrm{o}$ resultado mais satisfatório nesta etapa, observado na figura 8.

Tabela 3 - Tempo Padrão da Etapa1- Encaixe na Desenroladeira

\begin{tabular}{|c|c|c|c|c|c|c|c|}
\hline \multicolumn{8}{|c|}{ Tempo Padrão Etapa 1 Encaixe na Desenroladeira } \\
\hline \multicolumn{2}{|c|}{ Largura $<1000 \mathrm{~mm}$} & \multirow{2}{*}{$\frac{\text { Tempo (s) }}{65}$} & \multirow{2}{*}{$\frac{\text { Turma }}{\text { C }}$} & \multicolumn{2}{|c|}{ Largura $\geq 1000$} & Tempo (s) & Turma \\
\hline \multirow{3}{*}{ Espessura } & $<0,60$ & & & \multirow{3}{*}{ Espessura } & $<0,60$ & 66 & $\mathrm{C}$ \\
\hline & $\geq 0,60<1,90$ & 64 & C & & $\geq 0,60<1,90$ & 68 & C \\
\hline & $\geq 1,90$ & 89 & C & & $\geq 1,90$ & 108 & C \\
\hline
\end{tabular}

Fonte: Elaborado pelo autor, 2015 


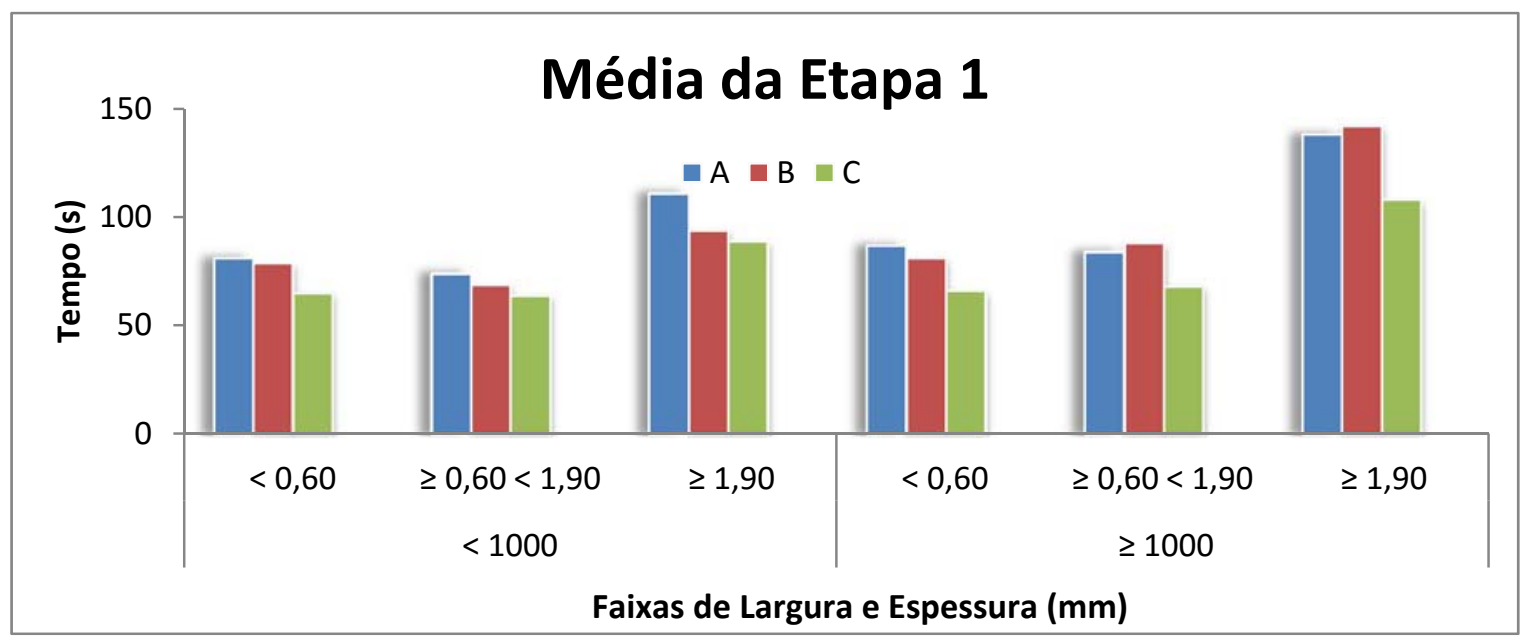

Fonte: Elaborado pelo autor, 2015

A Etapa 2 é também muito dependente da atuação do operador da desenroladeira, necessitando de uma preparação prévia da ponta da tira e conhecimento operacional para aplicar a melhor sequência de acionamentos durante 0 direcionamento desta até a máquina de solda.

A distribuição dos dados registrada na Figura 9 mostra que apenas $12 \%$ dos dados analisados estão acima de 40 segundos, considerando o tempo médio padrão o realizado pela equipe $C$ para 1.072 rolos, a redução estimada no tempo da etapa 2 é de aproximadamente 35 minutos por mês.

A Tabela 4, contém os tempos assumidos para esses rolos e na figura 28 está à média dos tempos realizados por cada turno em cada classe de largura e espessura.

Tabela 4 - Tempo Padrão da Etapa 2 - Deslocamento da ponta até a solda

\begin{tabular}{|c|c|c|c|c|c|c|c|}
\hline \multicolumn{8}{|c|}{ Tempo Padrão da Etapa 2 Deslocamento da ponta até a solda } \\
\hline \multicolumn{2}{|c|}{ Largura $<1000 \mathrm{~mm}$} & \multirow{2}{*}{$\frac{\text { Tempo }(\mathrm{s})}{33}$} & \multirow{2}{*}{$\frac{\text { Turma }}{\text { C }}$} & \multicolumn{2}{|c|}{ Largura $\geq 1000$} & \multirow{2}{*}{$\frac{\text { Tempo (s) }}{37}$} & \multirow{2}{*}{$\frac{\text { Turma }}{\mathrm{C}}$} \\
\hline \multirow{3}{*}{ Espessura } & $<0,60$ & & & \multirow{3}{*}{ Espessura } & $<0,60$ & & \\
\hline & $\geq 0,60<1,90$ & 32 & $A, C$ & & $\geq 0,60<1,90$ & 39 & C \\
\hline & $\geq 1,90$ & 32 & $A, C$ & & $\geq 1,90$ & 49 & $\mathrm{C}$ \\
\hline
\end{tabular}

Fonte: Elaborado pelo autor, 2015 
Figura 9- Média do set up da Etapa 2 - Deslocamento da Ponta até a solda .

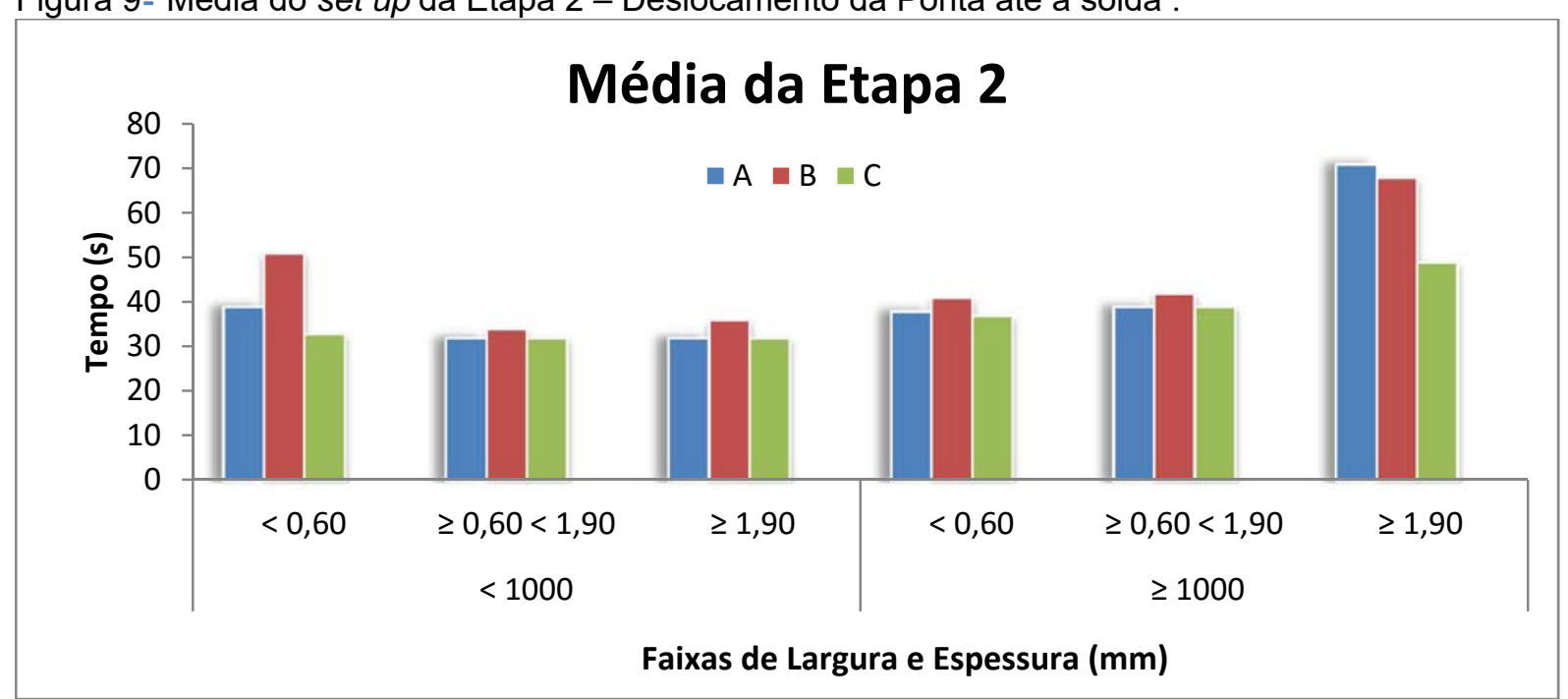

Fonte: Elaborado pelo autor, 2015

A etapa 3 referente a soldagem das pontas é automatizada, portanto, quase a totalidade dos dados estão compreendidos dentro do mesmo intervalo. A distribuição dos dados desta etapa mostra que apenas $13 \%$ dos dados analisados estão acima de 40 segundos, caracterizado por interrupções, que aconteceram por falha no equipamento. Inicialmente, esta etapa foi desconsiderada nos estudos para que manter foco na homogeneidade dos padrões e habilidades operacionais.

A etapa 4 é uma atividade de verificação, sendo seu tempo impactado apenas pela dúvida na qualidade da solda, o que obriga ao operador aplicar uma inspeção física, além da visual normalmente realizada. A distribuição dos dados desta etapa apresentou uma grande dispersão dos resultados das amostras como pode ser visto na Figura 10, o que demonstrou a diferença no tempo de tomada de decisão e/ ou na metodologia de comunicação empregada as equipes, haja visto que o fim desta atividade é determinado pela liberação do operador que fica no púlpito central. Atuando na padronização e treinamento dos operadores, seguindo como adequado o tempo realizado no turno que apresentou melhores resultados Tabela 5, haverá uma redução média de 11 segundos por rolo, proporcionando um ganho de aproximadamente 5 horas e 02 minutos em um mês.

Tabela 5 - Tempo Padrão da Etapa 4 - Inspeção da solda

Tabela 5 - Tempo Padrão da Etapa 4 Inspeção da solda

\begin{tabular}{|c|c|c|c|c|c|c|c|}
\hline \multicolumn{2}{|c|}{ Largura $<1000 \mathrm{~mm}$} & Tempo (s) & Turma & \multicolumn{2}{|c|}{ Largura $\geq 1000$} & Tempo (s) & Turma \\
\hline \multirow{3}{*}{ Espessura } & $<0,60$ & 39 & C & \multirow{3}{*}{ Espessura } & $<0,60$ & 40 & C \\
\hline & $\geq 0,60<1,90$ & 38 & $\mathrm{C}$ & & $\geq 0,60<1,90$ & 40 & $\mathrm{C}$ \\
\hline & $\geq 1,90$ & 34 & A & & $\geq 1,90$ & 51 & C \\
\hline
\end{tabular}

Fonte: Elaborado pelo autor, 2015 
Figura 10- Média do set up da Etapa 4 =- Inspeção da solda

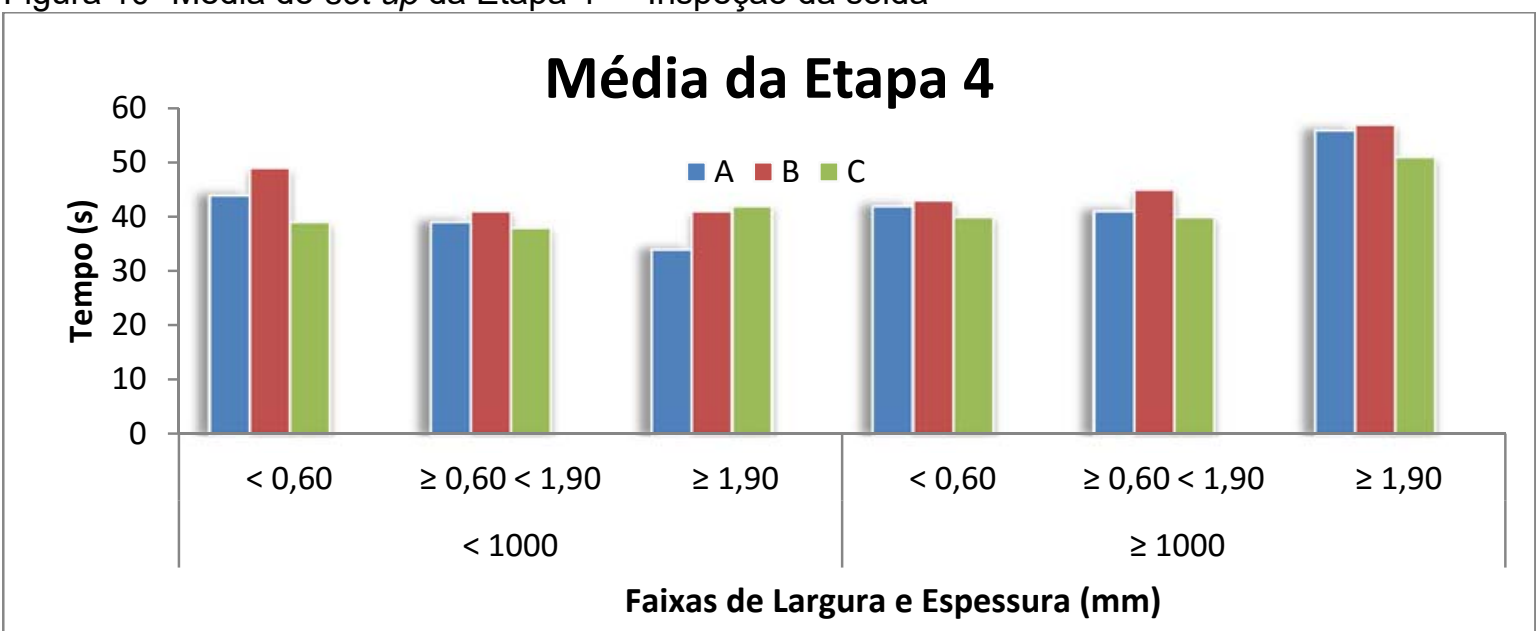

Fonte: Elaborado pelo autor, 2015

A etapa 5 , deslocamento da solda até a saída da linha, dependente exclusivamente das características do material em processo e da não intervenção da operação durante esta etapa. A distribuição dos dados desta etapa mostra que apenas $5 \%$ dos dados analisados estão acima de 40 segundos, portando, neste estudo não foi visualizado um ganho real para esta etapa, também sendo desconsiderada.

A etapa 6 , inspeção da tira, é totalmente dependente da atuação do inspetor de qualidade, necessitando de uma qualificação técnica e conhecimento da atividade a ser realizada. A distribuição dos dados desta etapa mostra que apenas $8 \%$ dos dados analisados estão acima de 90 segundos, atuando em treinamento dos inspetores e estipulando uma meta de tempo para tomada de decisão, pode proporcionar um ganho em 30 segundos nos 1.750 rolos que estiveram com tempo acima de 90 segundos, haveria um ganho de aproximadamente 42 minutos em um mês. A Tabela Tempo padrão - Etapa 6 Inspeção da Tira apresenta a média dos resultados realizados nos horários de melhor desempenho e a Figura 11 apresenta a média dos tempos realizados por cada turno.

\begin{tabular}{|c|c|c|c|c|c|c|c|}
\hline \multicolumn{2}{|c|}{ Largura $<1000 \mathrm{~mm}$} & \multirow{2}{*}{$\frac{\text { Tempo (s) }}{22}$} & \multirow{2}{*}{$\frac{\text { Turma }}{\mathrm{C}}$} & \multicolumn{2}{|c|}{ Largura $\geq 1000$} & \multirow{2}{*}{\begin{tabular}{|c|}
$\begin{array}{c}\text { Tempo } \\
(\mathrm{s})\end{array}$ \\
22 \\
\end{tabular}} & \multirow{2}{*}{$\begin{array}{c}\text { Turma } \\
\text { C }\end{array}$} \\
\hline \multirow{3}{*}{ Espessura } & $<0,60$ & & & \multirow{3}{*}{ Espessura } & $<0,60$ & & \\
\hline & $\geq 0,60<1,90$ & 23 & C & & $\geq 0,60<1,90$ & 25 & C \\
\hline & $\geq 1,90$ & 24 & C & & $\geq 1,90$ & 25 & C \\
\hline
\end{tabular}

Fonte: Elaborado pelo autor, 2015 
Figura 11- Média do set up da Etapa 6 - Inspeção da tira.

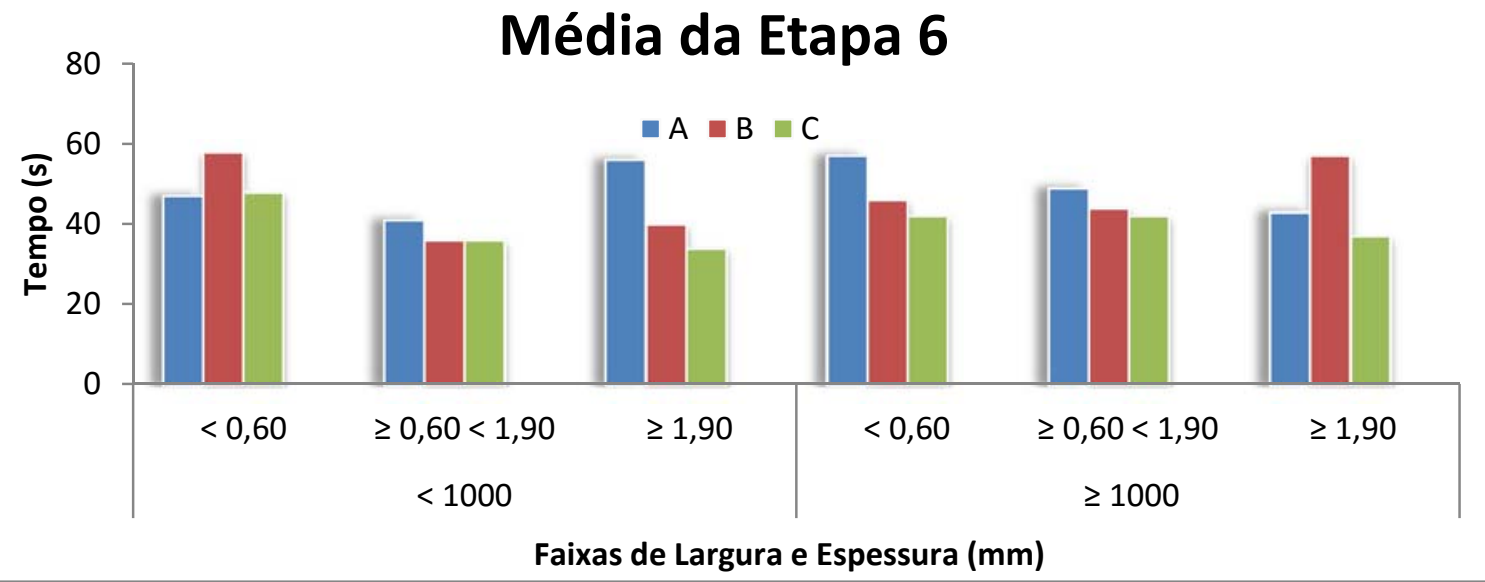

Fonte: Elaborado pelo autor, 2015

A etapa 7 é dependente da qualidade do material, o que determina a quantidade a ser descartada. Sendo este o principal e maior tempo de set-up encontrado, existe uma possibilidade de ganho no tempo de atuação da tesoura hidráulica, onde a forma construtiva deste equipamento permite o avanço da tira para um novo corte após a confirmação de que a navalha encontra-se na posição inicial, isso consiste em alterações na lógica utilizada. Este ganho está em aproximadamente 2 segundos por corte, e como cada descarte leva 11 segundos, seria de aproximadamente $18 \%$ do tempo realizado.

A Tabela 7 apresenta a média dos tempos realizados por cada turno e a Figura 12 Descarte de material com as melhores médias por classificação de material realizadas pelas equipes e que serão definidas como tempo padrão nesta etapa. Conforme já comentado, apesar desta etapa ter uma grande dependência da qualidade do material, se for aplicado a redução esperada em todos os rolos haverá uma diminuição de aproximadamente 3 horas e 51 minutos em cada mês medido.

\begin{tabular}{|c|c|c|c|c|c|c|c|}
\hline \multicolumn{2}{|c|}{ Largura $<1000 \mathrm{~mm}$} & \multirow{2}{*}{\begin{tabular}{|r} 
Tempo (s) \\
162
\end{tabular}} & \multirow{2}{*}{$\frac{\text { Turma }}{\mathrm{A}}$} & $\begin{array}{c}\text { Largura } \geq 1000 \\
\text { Espessura }\end{array}$ & \multirow{2}{*}{$\begin{array}{c}\text { Tempo (s) } \\
<0,60\end{array}$} & \multirow{2}{*}{$\frac{\text { Turma }}{170}$} & \multirow{2}{*}{$\frac{\text { Turma }}{\mathrm{C}}$} \\
\hline \multirow{3}{*}{ Espessura } & $<0,60$ & & & \multirow{2}{*}{ Espessura } & & & \\
\hline & $\geq 0,60<1,90$ & 161 & A & & $\geq 0,60<1,90$ & 171 & $A, C$ \\
\hline & $\geq 1,90$ & 138 & B & & $\geq 1,90$ & 172 & A \\
\hline
\end{tabular}

Fonte: Elaborado pelo autor, 2015 
Figura 12 - Etapa 7 - Descarte de material - Média do set up da Etapa 7.

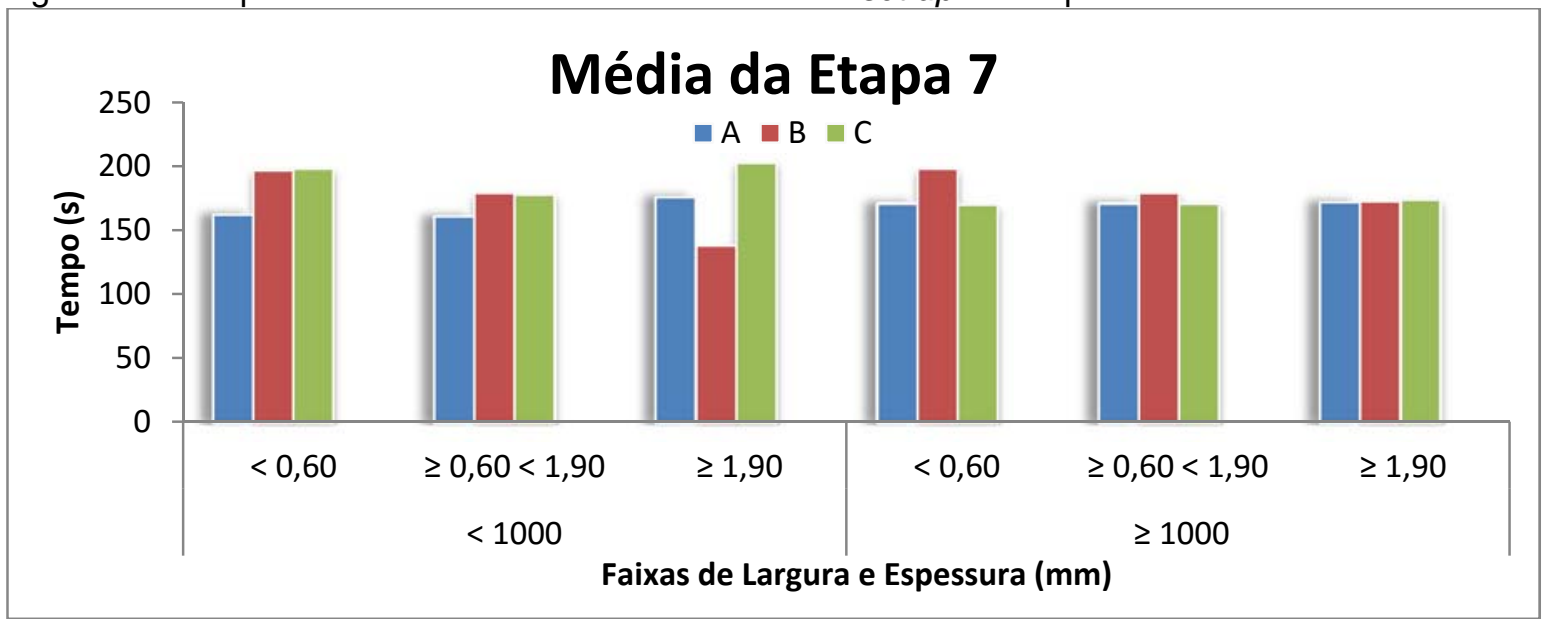

Fonte: Elaborado pelo autor, 2015

$\mathrm{Na}$ etapa 8, de encaixe da tira na enroladeira, apesar de consistir de acionamentos semi-automáticos, tem uma dependência operacional pela decisão correta do momento em que os eventos devem ser acionados, otimizando o acionamento de um evento simultaneamente quando outro evento já está ocorrendo.

A distribuição dos dados da etapa 8 mostra que $95 \%$ dos dados analisados estão no intervalo de 20 segundos, o que caracteriza uma boa atuação da operação em todos os turnos, isto também pode ser visualizado na Tabela 8. apresenta a média dos tempos realizados por cada turno e a Figura 13 as melhores médias por classificação de material realizadas pelas equipes e que serão definidas como tempo padrão nesta etapa.

Tabela 8 - Tempo Padrão da Etapa 8 Encaixe da Ponta na Enroladeira

\begin{tabular}{|c|c|c|c|c|c|c|c|}
\hline \multicolumn{8}{|c|}{ Tempo padrão - Etapa 8} \\
\hline \multicolumn{2}{|c|}{ Largura $<1000 \mathrm{~mm}$} & \multirow{2}{*}{\begin{tabular}{|r|} 
Tempo (s) \\
162 \\
\end{tabular}} & \multirow{2}{*}{$\frac{\text { Turma }}{\mathrm{C}}$} & \multicolumn{2}{|c|}{ Largura $\geq 1000$} & \multirow{2}{*}{$\begin{array}{r}\text { Tempo (s) } \\
170\end{array}$} & \multirow{2}{*}{$\begin{array}{c}\text { Turma } \\
\mathrm{A}, \mathrm{C}\end{array}$} \\
\hline \multirow{3}{*}{ Espessura } & $<0,60$ & & & \multirow{3}{*}{ Espessura } & $<0,60$ & & \\
\hline & $\geq 0,60<1,90$ & 161 & C & & $\geq 0,60<1,90$ & 171 & A \\
\hline & $\geq 1,90$ & 138 & A & & $\geq 1,90$ & 172 & C \\
\hline
\end{tabular}

Fonte: Elaborado pelo autor, 2015

Figura 13- Média do set up da Etapa 8.

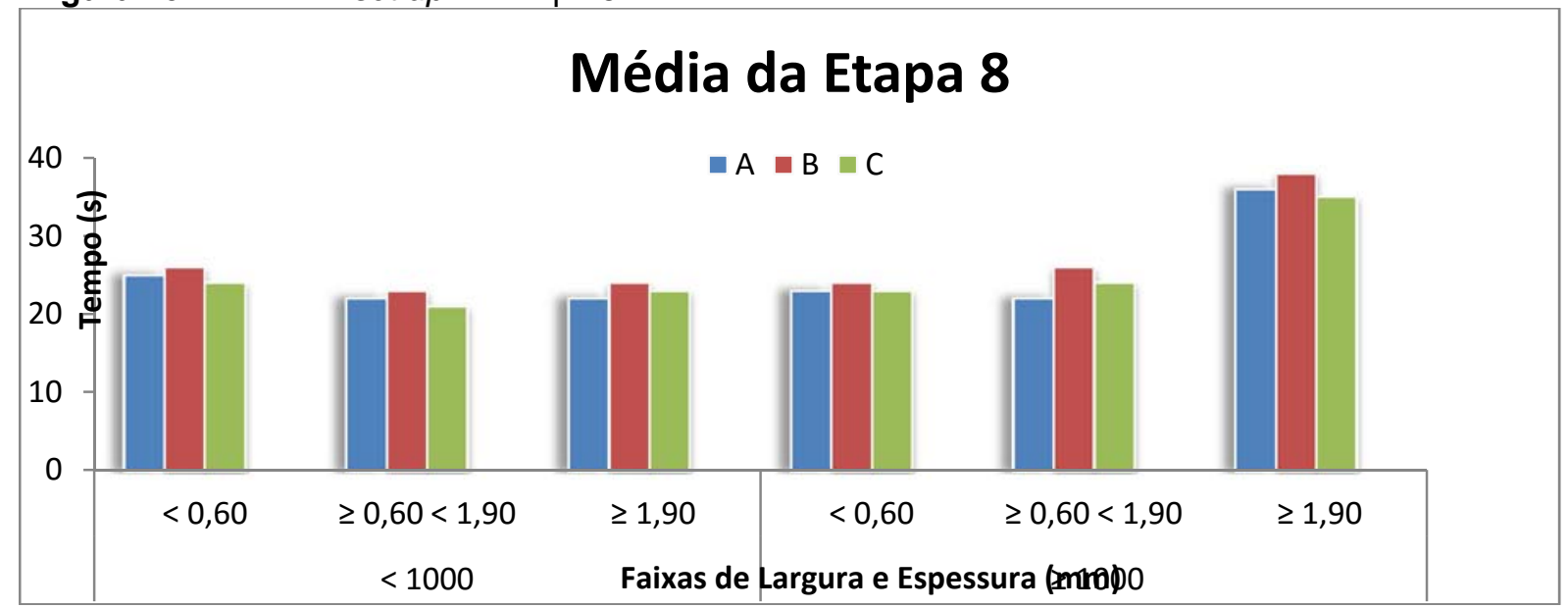

Fonte: Elaborado pelo autor, 2015 
A etapa 9, desaceleração final e saída da tira da desenroladeira, também depende exclusivamente do material em processo assim como a etapa 5 e suas limitações são a segurança do equipamento. Esta merece um estudo mais aprofundado para se obter possíveis reduções no tempo. A distribuição dos dados da etapa 9 mostra que $94 \%$ dos tempos realizados estão no intervalo de 15 a 40 segundos, e a média realizada por cada turno apresenta uma pequena variação devido a quantidade de material produzido em uma determinada espessura, ou seja, quanto mais fino for a espessura da tira, maior será o tempo desta etapa.

\section{RESULTADOS E DISCUSSÃO}

Os resultados obtidos demonstram um rendimento mais eficiente em algumas turmas, para as quais foram definidos os tempos padrões, o que não descarta a possibilidade de melhora ainda maior destes tempos. Tais resultados sugerem um acompanhamento da atividade in loco, com o objetivo de homogeneizar as melhores práticas, treinando e orientando os operadores para a necessidade de aplicar o conceito da melhoria continua, captando o engajamento na execução das atividades dentro do menor tempo possível. A partir disto, o acompanhamento entre os diferentes horários tem o foco de identificar as práticas realizadas neste turno para treinamento e normatização das atividades.

Atualmente o tempo de set-up na Linha está em torno de 8 minutos e 43 segundos, um tempo que pode ser reduzido para 7 minutos e 30 segundos com atuação em práticas operacionais, que são as grandes divergências encontradas neste estudo. Com essa redução no tempo de preparação, calcula-se um ganho médio de 23 minutos por turno, que irá proporcionar diretamente um ganho na produtividade da linha, conforme ilustrado na Tabela 9.

Tabela 9 - Resultados de aumento de produtividade

$\begin{array}{lr}\text { Produção Média Mensal (t) } & 30.000,00 \\ \text { Peso Médio de cada Rolo (t) } & 18,40 \\ \text { Qtd de Rolos/Mês } & 1.630,43 \\ \text { Tempo Set Up/Rolo atual (min.) } & 08: 43 \\ \text { Tempo Set Up/Mês (h) } & 236: 51: 57 \\ \text { Tempo Set Up/Rolo Reduzido (min.) } & 07: 30 \\ \text { Tempo Set Up/Mês (h) } & 203: 48: 16 \\ \text { Ganho de Set Up por Rolo (min.) } & 01: 13 \\ \text { Tempo Set Up Ganho /Mês (h) } & 33: 03: 42 \\ \text { Produtividade Efetiva da LI2 (t/h) } & 55,00 \\ \text { Disponibilidade de tempo (h) } & 33: 03: 42\end{array}$

Fonte: Elaborado pelo autor, 2015

\section{CONSIDERAÇÕES FINAIS}

Este estudo mostrou o quão importante é para a eficiência dos processos o acompanhamento detalhado das atividades. Verificou-se através de dados confiáveis, a variabilidade de tempo com que é executada uma mesma atividade, e a necessidade de estudar cada etapa com o objetivo de identificar as interferências, suas causas e ações de melhoria. 
A divisão dos tempos de set up em etapas facilitou bastante o estudo, condicionando e disciplinando o controle dos tempos e análise dos métodos de maneira individual e bastante eficiente.

Especificamente neste estudo, foi possível detectar pontos importantes a serem melhorados dentro do processo que causam demoras entre as etapas aumentando o tempo total de set up.

O benchmarking individual pode ser identificado e definido como padrão de melhores práticas, principal ação para um processo de disseminação e treinamento geral dos operadores, com objetivo de redução dos tempos de set up e consequente aumento da produtividade.

Ações simples de padronização das melhores práticas, que só tornaram-se possíveis após analise aprofundada dos tempos de set up, resultam em uma maior disponibilidade de oferta de produto acabado de cerca de $1800 \mathrm{t}$ a mais. Como proposta, além das ações em andamento e já implantadas, mediante a grande quantidade de dados a se analisar, sugere-se ainda a continuidade dos estudos com o intuito de detectar maiores oportunidades, disseminando junto ao nível operacional a importância e a necessidade destes conceitos na busca da melhoria continua e eficiência do processo.

\section{REFERÊNCIAS}

1 BAGGER, Karl K., CHAMONGE Fabio Tavares, DIAS, Danilo Rodrigues; FRANÇA FILHO, Rene de Oliveira. ESTUDO DE OTIMIZAÇÃO DO SET UP DE ENCAIXE DE PONTAS NA LINHA DE INSPEÇÃO 2 USIMINAS CUBATÃO Seminário de Laminação ABM Outubro 2013.

2 BAGGER, Karl K. CARVALHO, Amauri Dias; FRANÇA FILHO, Rene de Oliveira. GUERRA, Marcio Antonio. NOVA LINHA DE INSPEÇÃO DA COSIPA. Seminário de Laminação ABM Outubro 2003.

3 CAMPOS, Vicente Falconi. TQC: Gerenciamento da rotina do trabalho do dia-a-dia. Belo Horizonte. Fundação Christiano Otoni, 1992. - pg. 6; pg. 48 , 2009. - pg. 28

4 FIALHO, José Tarciso. FILHO, Airton Neubauer. O estudo de caso dirigido como metodologia de PESQUISA PARA A EDUCAÇAO À DISTÂNCIA (EAD), 2008. p. 79

5 LAUGENI, Fernando Piero. Administração da produção, editora Saraiva, 2005 - pg. 84 a 89.

6 MAFFEZZOLLI, Elaine Cristine F.; BOEHS, Carlos Gabriel Eggerts. Uma Reflexão Sobre o Estudo de Caso Como Método de Pesquisa, Revista da FAE, 2008.

7 SELEME, Robson. Métodos e Tempos Racionalização a produção de bens e Serviços. Editora IBPEX, 2009 - pg. 04 e 43.

8 YIN, Robert K.;Estudo de caso. Planejamento e métodos. $3^{a}$ edição. Porto Alegre. Editora Bookman, 2005. p. 27- 34. 